\title{
Anganwadi worker time use in Madhya Pradesh, India: a cross-sectional study
}

\author{
Anoop Jain ${ }^{1^{*}}$ D, Dilys M. Walker ${ }^{2}$, Rasmi Avula ${ }^{3}$, Nadia Diamond-Smith², Lakshmi Gopalakrishnan ${ }^{4}$, \\ Purnima Menon ${ }^{3}$, Sneha Nimmagadda ${ }^{5}$, Sumeet R. Patil ${ }^{5}$ and Lia C. H. Fernald ${ }^{4}$
}

\begin{abstract}
Background: Anganwadi Workers (AWWs) are a group of 1.4 million community health workers that operate throughout rural India as a part of the Integrated Child Development Services program. AWWs are responsible for disseminating key health information regarding nutrition, family planning, and immunizations to the women and children in their catchment area, while maintaining detailed registers that track key beneficiary data, updates on health status, and supply inventory beneficiaries. There is a need to understand how AWWs spend their time on all of these activities given all of their responsibilities, and the factors that are associated with their time use.

Methods: This cross-sectional study conducted in Madhya Pradesh, collected time use data from AWWs using a standard approach in which we asked participants how much time they spent on various activities. Additionally, we estimated a logistic regression model to elucidate what AWW characteristics are associated with time use.

Results: We found that AWWs spend substantial amounts of time on administrative tasks, such as filling out their paper registers. Additionally, we explored the associations between various AWW characteristics and their likelihood of spending the expected amount of time on preschool work, filling out their registers, feeding children, and conducting home visits. We found a positive significant association between AWW education and their likelihood of filling out their registers.

Conclusions: AWWs spend substantial amounts of time on administrative tasks, which could take away from their ability to spend time on providing direct care. Additionally, future research should explore why AWW characteristics matter and how such factors can be addressed to improve AWWs' performance and should explore the associations between Anganwadi Center characteristics and AWW time use.
\end{abstract}

Keywords: Time use, Anganwadi workers, Maternal \& Child Health, India, Madhya Pradesh

\section{Introduction}

\section{Background}

The role of community health workers (CHWs) has expanded considerably over the past 50 years, especially in low-and-middle-income countries (LMICs) [1]. A World Health Organization (WHO) report from 2016 highlights the chronic shortage of experienced health care workers in LMICs [2]. Many of these countries, for

\footnotetext{
* Correspondence: anoop_jain@hms.harvard.edu

${ }^{1}$ Harvard University, Boston, USA

Full list of author information is available at the end of the article
}

example, are simply unable to train and sustain an educated health workforce needed to ensure well-being and good health [2]. Thus, the burden of reducing morbidity and mortality, particularly in poor countries, often falls on the shoulders of a limited number of trained health care workers [2].

Task-shifting, a strategy proposed in 2004 for improving health outcomes, delegates the simplest health care tasks from health professionals (formally educated doctors, nurses, midwives, dentists, and psychologists) to local community members [3]. This approach could

C C The Author(s). 2020 Open Access This article is licensed under a Creative Commons Attribution 4.0 International License, which permits use, sharing, adaptation, distribution and reproduction in any medium or format, as long as you give appropriate credit to the original author(s) and the source, provide a link to the Creative Commons licence, and indicate if changes were made. The images or other third party material in this article are included in the article's Creative Commons licence, unless indicated otherwise in a credit line to the material. If material is not included in the article's Creative Commons licence and your intended use is not permitted by statutory regulation or exceeds the permitted use, you will need to obtain permission directly from the copyright holder. To view a copy of this licence, visit http://creativecommons.org/licenses/by/4.0/ The Creative Commons Public Domain Dedication waiver (http://creativecommons.org/publicdomain/zero/1.0/) applies to the data made available in this article, unless otherwise stated in a credit line to the data. 
reduce the workload on professional health care workers while ensuring that community members have their basic health care needs met. Historically, CHWs perform a far more integral role than simply providing the most basic health services. For example, Kahssay et al. suggest that "the most important developmental or promotional role of the $\mathrm{CHW}$ is to act as a bridge between the community and the formal health services in all aspects of health development" [4]. In bridging this gap, CHWs can help ensure that their beneficiaries are receiving the care that they need.

Anganwadi Workers (AWWs) are a group of 1.4 million CHWs that operate throughout rural India as a part of the Integrated Child Development Services (ICDS) program, which has been running since 1975 under the Ministry of Women and Child Development (MWCD). AWWs are based at Anganwadi centers (AWCs), where they provide a variety of services to approximately 800-1000 children under the age of six, and pregnant and lactating mothers $[5,6]$. AWWs are responsible for disseminating key health information regarding nutrition, family planning, and immunizations to the women and children in their catchment area, while maintaining detailed registers that track key beneficiary data, updates on health status, and supply inventory beneficiaries [7].

A number of studies have shown the positive impacts made by the ICDS AWW program. For example, one study used data from the 2005-2006 National Family Health Survey and found that ICDS improves linear growth for children from the poorest households [8]. Another study used data from the Demographic and Health Surveys (DHS) program from the same year and found that 0-2-year-old girls who receive intense supplementary feeding from ICDS are significantly taller than girls not receiving any supplementary feeding [9]. Reductions in the prevalence of underweight children have also been reported as a result of ICDS [10, 11]. However, service delivery gaps have also been reported. For example, several studies reported that many AWWs do not provide food to children or nutritional counseling to mothers when they are supposed to [12-14], that home visits are infrequent [15], and that the poorest households are often excluded from services [16].

AWWs are not unique in the problems of insufficient time being spent on key activities such as meal provision, health counselling, and home visits. For example, CHWs in a study in Ghana reported spending just only $10 \%$ of their daily work time on direct provision of services [17]. Similarly, Mazni et al. found that CHWs in their study in Tanzania spent only $57 \%$ of their daily time providing services [18]. Another study from Tanzania found that while CHWs spent $85 \%$ of their time between $9 \mathrm{am}$ and $11 \mathrm{am}$ providing health services, $90 \%$ of their time after 2 pm was spent on personal work [19].

A variety of factors could affect the amount of time CHWs, such as AWWs, spend on key activities and their overall performance. For example, a qualitative study conducted with CHWs in Nigeria, Burkina Faso, and Uganda found that while CHWs understood the voluntary nature of their work, they also felt that monetary incentives were critical to providing quality services [20]. CHWs from another qualitative study in India also reported that their pay was not commensurate with their effort and cited this as a cause of their lack of motivation to perform the duties of their job [21]. A number of other studies report similar findings that the lack of adequate or reliable remuneration leads to job dissatisfaction and stress, which undermines CHW performance [22-28].

Supervision, defined as a process through which supervisors monitor the work of peripheral workers and provide them with overall management [29], has also been found to alleviate some of the inefficiencies that stifle health worker productivity [24, 30-32]. Supervisor support, in the form of constructive feedback and goal setting, is also key to bolstering health worker productivity [33]. For example, results from a study in Ghana show that the effects of supervision on CHW productivity depend on how supportive the supervisors were [17]. Another study from Mali found that dedicated monthly supervision with feedback tailored to each $\mathrm{CHW}$ was associated with gains in CHW productivity [34].

The purpose of this paper was to build on this prior research using the context of AWWs in Madhya Pradesh, India. Our aims were to 1) describe how much time AWWs report spending on 11 major activities in their day-to-day work, ${ }^{1}$ 2) how this reported time deviates from the expected amount of time on the four activities deemed most important by the government (section 2.4.1), and 3) to elucidate what AWW characteristics are associated with AWWs spending the expected amount of time on these four activities. We hypothesized that there would be deviations from expected time spent on activities due to various AWW characteristics such as age and caste, along with the administrative burden placed on AWWs that might affect their time management.

\section{Methods}

Study area

This time use study is a part of a larger program evaluation of a mobile health application intervention called intended to improve AWW performance by automating

\footnotetext{
${ }^{1}$ From here forward, work refers to Anganwadi work, not the household work that AWWs are also likely to be engaged in
} 
the 11 registers they are required to complete, ${ }^{2}$ providing helpful reminders, and ensuring that they have access to essential resources such as automatic plotting of growth monitoring charts) and educational videos on birth preparedness, complementary feeding, family planning and sanitation. This study took place in Madhya Pradesh, where health care delivery is particularly difficult given the state's geography (over $30 \%$ of its land area is covered by forest) [35]. Additionally, much like other states in India, the private sector dominates in Madhya Pradesh [36]. Furthermore, Madhya Pradesh has a high burden of under-five mortality at 69 per 1000 live births in 2015 , where over $43 \%$ of children between the ages of $0-5$ are stunted, $55 \%$ of pregnant women aged 15-49 are anemic, only $50 \%$ of children between the ages of $12-23$ months are fully immunized, and only $8.3 \%$ of mothers have had full antenatal care [37].

\section{Participants and sampling}

Our sample included 554 AWWs from six districts in Madhya Pradesh. These AWWs were a part of the evaluation endline survey, which took place during December 2018 and January 2019. A full description of the evaluation sampling strategy can be found in previously published work [38]. A full list of AWW characteristics can be found in Table 1.

\section{Measurement tool}

We collected time use data from AWWs using a standard approach, which has been used in several previous studies. For example, this method has previously been used in the Women's Empowerment in Agriculture survey conducted in Uganda and Bangladesh [39]. Similarly, Kahneman et al. used a version of stylized questions in their study that examined how 1108 women in the United States spent their time [40]. This is a method that involves asking respondents questions about how much time they spend conducting various activities as opposed to asking respondents how they spent their time in a given time range [41]. Trained interviewers questioned each AWW at the end of the day they visited the center about the time spent conducting each prespecified activity on the day of the interview. For example, AWWs were asked questions such as, "how much time did you spend updating paper registers?" and "how much time did you spend conducting growth monitoring?". Responses were recorded in terms of the number of hours and minutes spent on the activity. Thus, we did not ask respondents to recall what they did in prespecified time intervals.

\footnotetext{
${ }^{2}$ At the time of this survey, none of the AWWs in our sample had given up their paper registers as they were still being used in a backup capacity
}

Table 1 AWW Characteristics

\begin{tabular}{|c|c|c|c|}
\hline & Category & Number & Percentage \\
\hline \multirow[t]{5}{*}{ Caste } & Scheduled Caste & 52 & $9.40 \%$ \\
\hline & Scheduled Tribe & 267 & $48.20 \%$ \\
\hline & Other Backwards Class & 126 & $22.70 \%$ \\
\hline & General Caste & 109 & $19.70 \%$ \\
\hline & Total & 554 & $100.00 \%$ \\
\hline \multirow[t]{4}{*}{ Experience } & $<10$ years & 174 & $31.40 \%$ \\
\hline & 10-18 years & 242 & $43.70 \%$ \\
\hline & $>19$ years & 138 & $24.90 \%$ \\
\hline & Total & 554 & $100.00 \%$ \\
\hline \multirow[t]{3}{*}{ Education } & Below 11th Grade & 261 & $47.10 \%$ \\
\hline & Above 11th & 293 & $52.90 \%$ \\
\hline & Total & 554 & $100.00 \%$ \\
\hline \multirow[t]{4}{*}{ Age } & $<36$ years & 204 & $36.80 \%$ \\
\hline & $36-44$ years & 169 & $30.50 \%$ \\
\hline & $>44$ years & 181 & $32.70 \%$ \\
\hline & Total & 554 & $100.00 \%$ \\
\hline \multirow[t]{3}{*}{ Other Work } & Yes & 29 & $5.20 \%$ \\
\hline & No & 525 & $94.80 \%$ \\
\hline & Total & 554 & $100.00 \%$ \\
\hline \multirow[t]{4}{*}{ Family Size } & $<4$ members & 69 & $12.50 \%$ \\
\hline & 4-7 members & 310 & $55.90 \%$ \\
\hline & $>7$ members & 175 & $31.60 \%$ \\
\hline & Total & 554 & $100.00 \%$ \\
\hline \multirow[t]{2}{*}{ Has a helper } & Yes & 463 & $83.60 \%$ \\
\hline & No & 91 & $16.40 \%$ \\
\hline \multirow[t]{2}{*}{ Wealth $^{a}$} & Median & Min & Max \\
\hline & 17 & 5 & 29 \\
\hline
\end{tabular}

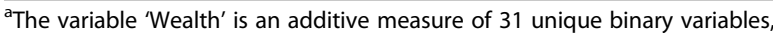
each of which represents a different household asset such as animals and livestock and durable goods

Developing the final list of activities was an iterative process, which began in 2018 with a pilot study. We first shadowed 36 AWWs and noted all of their daily activities, and the amount of time spent doing each one. This pilot study helped us develop a list of 64 key activities that could be grouped in to nine categories. We also used the guidelines issued by the Ministry of Women and Child Development to gain an understanding about the key activities that AWWs are responsible for executing on a daily basis, along with the amount of time that should be spent on these activities [42].

Informed consent was obtained from all participants before any interviews were conducted. Study protocols have been reviewed and approved by institutional review boards at the University of California, Berkeley (reference number: 2016-08-9092), and the India-based Suraksha Independent Ethics Committee (protocol number: 
Table 2 Summary of outcome variables (in minutes), $n=554$

\begin{tabular}{|c|c|c|c|c|}
\hline Time Spent On & Median & Max & Mean & Percent of Total Mean Time \\
\hline Home Visits & 30 & 120 & 32.4 & $9 \%$ \\
\hline Feeding & 60 & 120 & 52.8 & $15 \%$ \\
\hline Preschool Work ${ }^{a}$ & 90 & 240 & 95.3 & $26 \%$ \\
\hline Paper Register Work & 47.5 & 180 & 51.1 & $14 \%$ \\
\hline Updating Mobile App & 0 & 180 & 13.2 & $4 \%$ \\
\hline Childcare & 30 & 180 & 41.4 & $11 \%$ \\
\hline Growth Monitoring & 0 & 120 & 9.3 & $3 \%$ \\
\hline Meetings & 0 & 240 & 10.2 & $3 \%$ \\
\hline Other ICDS Work & 10 & 240 & 22 & $6 \%$ \\
\hline Non-ICDS Work & 0 & 270 & 13.2 & $4 \%$ \\
\hline Resting & 0 & 210 & 18.5 & $5 \%$ \\
\hline Total & & & 359.4 & \\
\hline
\end{tabular}

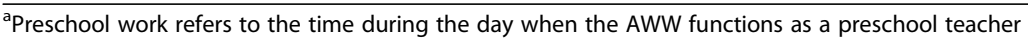

2016-08-9092). The trial is registered with the ISRCTN registry (https://doi.org/10.1186/ISRCTN83902145).

\section{Measures \\ Outcomes}

We studied eleven outcomes which are the amount of time spent (in minutes) on eleven activities listed in Table 2 based on the self-reports by the AWWs. The Ministry of Women and Child Development (MWCD) have identified the first four activities as the core tasks and have specified the expected amount of time that should be spent on each one. For example, AWWs are expected to spend $60 \mathrm{~min}$ conducting home visits, 30 min feeding children at the Anganwadi Centre, $120 \mathrm{~min}$ on preschool work, and $30 \mathrm{~min}$ on paper registers every day. For each of these four activities, therefore, we created a binary outcome - 1 if an AWW spent the expected time or more on the activity, and 0 otherwise.

\section{Independent variables}

We modeled AWW caste $^{3}$ (tertiles, bottom as reference), age, education (above/below 11th grade), years of experience working as an AWW (tertiles, bottom as reference), whether or not they work another job (yes/no), whether or not they have a helper (yes/no), wealth (additive index of 30 components), and family size as defined as the number of all family members living together (tertiles, bottom as reference). These variables were selected based on our hypotheses about factors that might be associated with the primary outcomes.

\footnotetext{
${ }^{3}$ Scheduled tribe, scheduled caste, other backward class, and general caste are the four broad caste categories used in India's system of affirmative action [41]. We used general caste as the reference category. Historically, scheduled castes and scheduled tribes have been the most marginalized groups in India.
}

\section{Analytical approach}

The general form of the model that we estimated for understanding what factors $(\mathbf{X})$ are associated with spending the expected amount of time on a core activity was: logit $\left(\pi_{\mathrm{ij}}\right)=\beta_{0}+\beta_{1} \mathbf{X}_{\mathrm{ij}}+\varepsilon_{\mathrm{ij}}$, where $\pi_{\mathrm{ij}}$ represents the odds for a given outcome for AWW $i$ in village $j$. We exponentiated our results so that estimates the odds of spending the expected time, or more, on the given activity for all of the independent variables specified above.

\section{Results}

\section{Sample characteristics}

Among the 260 AWWs with the mobile application and 294 AWWs without the application in our sample, the largest share belonged to the Scheduled Tribe category (44\%) (Table 1). In our sample, $36 \%$ of AWWs had between 10 and 18 years of experience working as AWWs. There was an even split in educational attainment, and the average age of AWWs in our sample was 40. Furthermore, $94 \%$ of the AWWs reported having no other form of work.

\section{Overall time use}

On average, the AWWs in our sample spent a total of $360 \mathrm{~min}$ (6 h) working per day, which is the number of hours AWWs are expected to work (Table 2). The activity that took up the most time during the day was preschool work (26\%); AWWs spent the least amount of time attending meetings and on growth monitoring (3\% of their total workday on each activity). Home visits accounted for $9 \%$ of daily work time, while feeding and paper register work took up 15 and $14 \%$ of daily work time, respectively. Other work related to ICDS (opening and closing the AWW, for example) accounted for $6 \%$ of daily work time, while $5 \%$ of daily work time was spent 
resting. Overall, the AWWs in our sample spent a total of $52 \%$ of their daily time directly serving children ( $26 \%$ on preschool work, $15 \%$ on feeding, and $11 \%$ on childcare).

\section{Home visits}

In our sample, $331 \mathrm{AWWs}$ reported conducting home visits on the day of our data collection. These AWWs reported spending an average of $32 \mathrm{~min}$ conducting home visits, which is 28 min less than the expected daily time specified by the government (Table 3 ). The majority $(65 \%)$ of AWWs in our sample spent less than the expected amount of daily time conducting home visits. We found that higher odds of spending the expected amount of time or more on home visits was significantly associated with being Scheduled Tribe (odds-ratio: 1.69, $95 \%$ CI 0.97, 2.94) after controlling for all other covariates (Table 4 ).

\section{Feeding}

AWWs in our sample reported spending an average of 52 min on feeding, which is 22 min more than the expected daily time. The majority (90\%) of AWWs in our sample spent more than the expected amount of daily time on feeding (Table 3). We did not find any significant associations for feeding.

\section{Preschool work}

AWWs in our sample reported spending an average of 95 min per day on preschool work, which is 25 min less than the expected daily time. There was a fairly even split between the percent of AWWs who spent below and above the expected amount of daily time on preschool work (55 and 45\% respectively) (Table 3 ). We did not find any significant associations for preschool work.

\section{Paper registers}

AWWs in our sample reported spending an average of $51 \mathrm{~min}$ filling out their paper registers, which is $21 \mathrm{~min}$ more than the expected daily time. The majority (83\%) of AWWs in our sample spent more than the expected amount of daily time on paper registers (Table 3). We also found AWW from a Scheduled Tribe had lower odds of spending the expected amount of time or more on paper registers (odds-ratio: 0.34, 95\% CI 0.14, 0.79) (Table 4), after controlling for all other covariates. We found that higher odds of spending the expected amount of time or more on paper registers associated with the AWW having attained above the median level of education (11th grade) (odds-ratio: 2.14, 95\% CI 1.22, 3.73) (Table 4), after controlling for all other covariates. We did not find any other significant associations for paper registers.

\section{Discussion}

Overall, our findings suggest that caste, education, having helpers and having other jobs were the associated time use. Specifically, our findings show no significant associations between AWW age and the likelihood that they spend the expected amount of time on home visits, feeding, preschool work, or paper register work. Scheduled Caste AWWs were more likely to spend the expected amount of time conducting home visits compared to general caste AWWs but were less likely to spend the expected amount of time on feeding and paper register work than their general caste counterparts. AWWs with helpers were almost twice as likely to spend the expected amount of time on paper register work compared to AWWs without helpers. Furthermore, AWWs who had at least an 11th grade education were more than twice as likely to spend the expected amount of time on paper register work than AWWs with less than an 11th grade education.

Additionally, our results indicate that on average, the AWWs in our sample spent a total of $52 \%$ of their daily time directly serving children which is encouraging given that children are a core focus of the ICDS program. However, the AWWs in our sample spent only $9 \%$ of their daily work time conducting home visits and $3 \%$ of their time on growth monitoring. Conducting home visits, and measuring child height and weight, are essential as they help ensure that children are meeting their growth targets. There are several possible explanations for these findings. For example, AWCs often do not have growth monitoring charts available. In fact, 30 and $21 \%$ of AWCs in two separate studies did not have growth charts present, respectively [43, 44], while $49 \%$ of the AWCs in our sample did not have growth charts. Another reason is that AWWs do not measure every day, and thus enumerators may not have visited a given AWW the day she was supposed to conduct child measurements. Similarly, AWWs may not have been

Table 3 Percent of AWWs that spent expected daily time on home visits, feeding, preschool work, and paper registers

\begin{tabular}{llll}
\hline Activity & Expected daily time (mins) & Percent below & Percent above \\
\hline Home visits & 60 & $65.7 \%$ & $34.3 \%$ \\
Feeding & 30 & $10.3 \%$ & $89.7 \%$ \\
Preschool work & 120 & $54.9 \%$ & $45.1 \%$ \\
Paper registers & 30 & $17 \%$ & $83 \%$ \\
\hline
\end{tabular}


Table 4 Regression results ${ }^{\mathrm{a}}$

\begin{tabular}{|c|c|c|c|c|}
\hline & Home Visits & Feeding & Preschool Work & Paper Register Work \\
\hline \multirow[t]{2}{*}{ Scheduled caste } & 1.84 & 4.08 & 0.81 & 0.65 \\
\hline & $(0.87,3.89)$ & $(0.49,34.2)$ & $(0.39,1.65)$ & $(0.21,2.01)$ \\
\hline \multirow[t]{2}{*}{ Scheduled tribe } & $1.69^{*}$ & $0.48^{*}$ & 0.76 & $0.34^{* *}$ \\
\hline & $(0.97,2.94)$ & $(0.20,1.11)$ & $(0.46,1.28)$ & $(0.14,0.79)$ \\
\hline \multirow[t]{2}{*}{ Other backward class } & 1.17 & 1.48 & 0.81 & 0.96 \\
\hline & $(0.64,2.13)$ & $(0.52,4.25)$ & $(0.47,1.41)$ & $(0.35,2.58)$ \\
\hline \multirow[t]{2}{*}{ Above 11th grade } & 1.26 & 0.75 & 1.29 & $2.13^{* * *}$ \\
\hline & $(0.84,1.82)$ & $(0.39,1.44)$ & $(0.87,1.91)$ & $(1.22,3.73)$ \\
\hline \multirow[t]{2}{*}{ 36-44 years old } & 1.12 & 0.78 & 1.29 & 1.59 \\
\hline & $(0.69,1.83)$ & $(0.36,1.68)$ & $(0.81,2.05)$ & $(0.82,3.08)$ \\
\hline \multirow[t]{2}{*}{ Above 44 years old } & 1.43 & 0.65 & 1.10 & 1.06 \\
\hline & $(0.80,2.53)$ & $(0.26,1.62)$ & $(0.64,1.92)$ & $(0.52,2.18)$ \\
\hline \multirow[t]{2}{*}{$10-18$ years of experience } & 1.45 & 1.35 & 0.82 & 1.37 \\
\hline & $(0.87,2.42)$ & $(0.61,2.96)$ & $(0.51,1.33)$ & $(0.69,2.74)$ \\
\hline \multirow[t]{2}{*}{ Above 19 years of experience } & 1.13 & 1.58 & 0.81 & 0.95 \\
\hline & $(0.59,2.14)$ & $(0.57,4.38)$ & $(0.44,1.49)$ & $(0.41,2.16)$ \\
\hline \multirow[t]{2}{*}{ Other work } & 1.70 & 2.61 & 0.45 & 1.03 \\
\hline & $(0.78,3.73)$ & $(0.34,20.21)$ & $(0.19,1.05)$ & $(0.32,3.27)$ \\
\hline \multirow[t]{2}{*}{ Wealth } & 0.97 & 1.02 & 1.03 & 0.96 \\
\hline & $(0.92,1.02)$ & $(0.94,1.11)$ & $(0.98,1.09)$ & $(0.89,1.02)$ \\
\hline \multirow[t]{2}{*}{ 4-7 family members } & 1.24 & 1.18 & 1.05 & 0.76 \\
\hline & $(0.68,2.25)$ & $(0.48,2.92)$ & $(0.61,1.82)$ & $(0.34,1.70)$ \\
\hline \multirow[t]{2}{*}{ Above 7 family members } & 1.45 & 1.20 & 1.23 & 0.89 \\
\hline & $(0.76,2.77)$ & $(0.45,3.21)$ & $(0.67,2.26)$ & $(0.37,2.14)$ \\
\hline \multirow[t]{2}{*}{ Has helper } & 0.78 & 1.09 & 1.13 & $1.84^{* *}$ \\
\hline & $(0.48,1.28)$ & $(0.53,2.25)$ & $(0.69,1.81)$ & $(1.03,3.25)$ \\
\hline \multirow[t]{2}{*}{ Constant } & 0.34 & $7.19^{* *}$ & 0.46 & $8.19^{* *}$ \\
\hline & $(0.09,1.23)$ & $(1.01,51.48)$ & $(0.14,1.53)$ & $(1.44,46.69)$ \\
\hline Observations & 554 & 554 & 554 & 554 \\
\hline
\end{tabular}

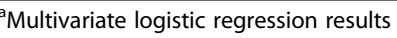

$(95 \% \mathrm{Cl}))$

${ }^{* * *} p<0.01,{ }^{* *} p<0.05,{ }^{*} p<0.1$

required to conduct any home visits on the day enumerators visited them; ICDS has also issued guidelines on when children, and pregnant and lactating mothers need to be visited at home and AWWs often group multiple visits on a single day as per this schedule.

Furthermore, $83 \%$ of the AWWs in our sample reported spending more than the expected amount of time on filling out paper registers. This could be an indication of the fact that the expected amount of time that AWWs should spend on activities such as paper registers could be unrealistic, especially given the fact that each AWW is typically responsible for serving approximately 1000 beneficiaries [43] and maintaining eleven registers. Spending so much time on completing registers is also evidence of how CHWs often feel compelled to spend time reporting and evaluating in order to help produce 'numerical narratives' to demonstrate successful public health programs as imagined by their superiors [44]. Such stringent reporting guidelines and requirements have been found to undermine an AWW's ability to engage in activities that would help them develop a thorough understanding of the health needs of their beneficiaries (via activities such as home visits, for example) [45]. The reporting requirements in the context of this study were further compounded by the fact that AWWs equipped with the mobile application were also required to use paper registers as a failsafe.

Various AWW characteristics were associated with the amount of time that they spend on essential activities such as home visits, feeding children, register work, and 
preschool work. For example, AWW caste is a complex concept because it relates to social marginalization, educational qualifications, as well as socio-economic status. Stifled educational opportunities early in life could explain why low caste AWWs spend less time filling out paper registers than higher caste AWWs. Additionally, caste divisions within a community could undermine an AWWs ability to perform her job (if she is of low caste) [46]. Perhaps this could help explain why the Scheduled Tribe (historically marginalized group) AWWs in our study are less likely to spend the expected amount of time on feeding. Perhaps, they serve smaller population than general caste AWWs and thus spend less time doing paper register work when compared to general caste AWWs. On the other hand, Scheduled Tribe AWWs spent much more time on home visits perhaps because they serve tribal areas which can be spread out requiring more travel time. The focus of this study was not to identify how caste or other socio-economics characteristics play a role in AWW performance and we don't have substantive data to explore such reasons further. However, this can be a useful future research area.

Additionally, AWWs in some parts of India have reported significant stress and job dissatisfaction [47], and often complain about being overworked, job insecurity, and the lack of proper AWC infrastructure [48, 49]. These factors, coupled with the fact that AWWs often report delays in being paid their salaries [50] could undermine an AWW's motivation to spend adequate amounts of time performing her duties, and thus their impact. In fact, performance pay for AWWs has been found to significantly reduce underweight prevalence, thus demonstrating that AWWs perform better when they are paid appropriately [51]. The fact that AWW salaries are delayed might also be why some AWWs have to take up other jobs, which could explain why they are able to spend less time performing key tasks such as preschool work. This also raises the question about the extent to which the tasks performed by other groups of CHWs in India, such as Auxiliary Nurse-Midwifes and Accredited Social Health Workers and AWW helpers (95\% of AWWs in our sample reported having a helper) might complement the work performed by AWWs. Our study only included AWWs, but ANMs, ASHAs, and helpers could be making up for work not done by AWWs in a given village, something that should be further studied.

There are several limitations to this study. First, as noted above, we collected data about how AWWs spent their time during one presumably representative day with no direct observation. This approach is prone to error given that it is asking respondents to recall how much time they spent on various activities, pointing to a flaw in self-reported data [52]. Furthermore, self- reported data could be problematic given top down reporting pressures, which have been found to create a drive for 'right' numbers leading to inaccurate reporting [53] Next, our outcomes were constructed as binary variables, indicating only whether an AWW spent above or below the expected amount of time on an activity. This approach did not capture whether or not the AWWs interviewed felt as though they had completed their necessary tasks of the day, the efficiency with which tasks were executed, or their motivation to complete a task, which could also influence time spent on activities. At a certain point, spending too much or too little time on an activity might be problematic. Spending too much time could take away from an AWW's ability to spend time on other essential tasks, while not spending enough time on certain tasks could be associated with poor outcomes. Therefore, time use, while useful, is not necessarily a performance metric. Additionally, our survey did not capture data about AWW duties and responsibilities in her own home. AWWs with a greater burden of responsibilities in their own homes might be less able to spend the expected amount of time on their duties in the AWC. It is also unclear whether the government's recommendations for expected time to be spent per activity are based in evidence. Our results show that perhaps future research is needed to better understand the appropriate amounts of times that should be spent on activities. Finally, we only collected data from each respondent for 1 day due to logistical constraints. However, it is more common to collect at least 2 days' worth of data for reliability issues, and in order to capture data on less frequently occurring activities [41]. In the context of this study, this meant that we only collected time use data on home visits from 331 AWWs.

Despite these limitations, to our knowledge, this is perhaps the only study which has looked at how AWWs spend their time in a diverse sample of more than 400 villages from six districts and assessed their time use against government guidelines. We have also identified that certain AWW socio-demographic characteristics are strongly associated with their time-use outcomes which can guide future research, to study how and why they matter, or direct training and AWW support efforts.

\section{Conclusion}

Overall, we find that AWWs spend a big share of their work time on filling out their paper registers even when a smartphone-based application is available, and they had been given the option to not use the paper registers. This could take away from their ability to spend the expected amount of time conducting home visits, and thus serving adolescent girls, pregnant women, and lactating mothers, and is something that can be addressed by the government. Second, we find that the current guidelines 
on expected time spent on core tasks may need to be revised to better account for the work realities of AWWs. For example, conducting home-visits every-day is not even needed as per ICDS's own home-visit schedule and AWWs can combine multiple visits on a single day to save on travel time. Perhaps a newer set of guidelines that recognize varied work conditions faced by the AWWs and provide guidance and training resource on how to effectively plan and manage daily workload would be a useful resource, especially as the paper registers are phased out across the country. Additionally, ICDS should ensure that AWCs are equipped with all the necessary supplies and tools for AWWs to perform their tasks. For example, if AWWs had reliable access to records from the mobile application, they may not have needed to also maintain paper registers as a failsafe. Finally, immutable characteristics such as caste are significant predictors of an AWW's ability to spend the expected amount of time on various activities. Future research can explore why these characteristics matter and how such factors can be addressed to improve AWWs' performance.

\section{Abbreviations}

AWWs: Anganwadi workers; CHWs: Community health workers; LMICs: Lowand-middle-income countries; WHO: World Health Organization; ICDS: Integrated Child Development Services; MWCD: Ministry of Women and Child Development; AWCs: Anganwadi Centers; DHS: Demographic and Health Surveys

\section{Acknowledgements}

The authors would like to acknowledge all of the Anganwadi Workers and data collectors who made this study possible.

\section{Authors' contributions}

AJ - Conceptualization, formal analysis, writing (original draft), writing (reviewing \& editing); DW - writing (original draft), writing (reviewing \& editing); RA - writing (reviewing \& editing); NDS - writing (reviewing \& editing); LG - writing (reviewing \& editing); PM - writing (reviewing \& editing); SN - writing (reviewing \& editing); SRP - writing (reviewing \& editing); LCHF - Conceptualization, formal analysis, writing (original draft), writing (reviewing \& editing). All authors have read and approved the manuscript.

\section{Funding}

This study is funded by Grant No. OPP1158231 from the Bill and Melinda Gates Foundation (BMGF) to the University of California, San Francisco and University of California, Berkeley. BMGF funded the larger CAS intervention evaluation, and provided support in the scale up of the CAS_ICDS program.

\section{Availability of data and materials}

The datasets analyzed during the current study are not publicly available given that the research team has not completed its analysis but are available from the corresponding author on reasonable request.

\section{Ethics approval and consent to participate}

Informed written consent was obtained from all participants before any interviews were conducted. Study protocols have been reviewed and approved by institutional review boards at the University of California, Berkeley (reference number: 2016-08-9092), and the India-based Suraksha Independent Ethics Committee (protocol number: 2016-08-9092).

\section{Consent for publication}

Not applicable.

\section{Competing interests}

The authors declare that they have no competing interests.

\section{Author details}

${ }^{1}$ Harvard University, Boston, USA. ${ }^{2}$ University of California San Francisco, San Francisco, USA. International Food Policy Research Institute, Washington, DC, USA. ${ }^{4}$ University of California Berkeley, Berkeley, USA. ${ }^{5}$ NEERMAN, Center for Causal Research and Impact Evaluation, Mumbai, India.

Received: 12 March 2020 Accepted: 22 October 2020

Published online: 07 December 2020

\section{References}

1. Pallas SW, Minhas D, Pérez-Escamilla R, Taylor L, Curry L, Bradley EH. Community health workers in low- and middle-income countries: what do we know about scaling up and sustainability? Am J Public Health. 2013; 103(7):e74-82. https://doi.org/10.2105/AJPH.2012.301102.

2. WHO. Global strategy on human resources for health: workforce 2030 . Geneva: World Health Organization; 2016.

3. JLI. Human resources for health. Overcoming the crisis. Cambridge: Global Health Initiative/Harvard UniversityPress; 2004.

4. Kahssay H, Taylor M, Berman P. Community health workers: the way forward. Geneva: World Health Organization; 1998.

5. Rao N, Kaul V. India's integrated child development services scheme: challenges for scaling up. Child Care Health Dev. 2018;44:31-40.

6. Gragnolati M, Bredenkamp C, Gupta MD, et al. ICDS and persistent Undernutrition: strategies to enhance the impact. Econ Polit Wkly. 2006;41: 1193-201.

7. USAID. Case studies of large-scale community health worker programs; 2014.

8. Kandpal E. Beyond average treatment effects: distribution of child nutrition outcomes and program placement in India's ICDS. World Dev. 2011;39(8): 1410-21. https://doi.org/10.1016/j.worlddev.2010.12.013.

9. Jain M. India's struggle against malnutrition-is the ICDS program the answer? World Dev. 2015;67:72-89. https://doi.org/10.1016/j.worlddev.2014. 10.006.

10. Mittal N, Meenakshi JV. Utilization of ICDS services and their impact on child health outcomes: evidence from three east Indian states; 2015. Delhi School of Economics. Centre for Development Economics Working Paper 247 (October, 46 pages).

11. Deolalikar AB. Attaining the millennium development goals in India: reducing infant mortality, child malnutrition, gender disparities, and hungerpoverty, and increasing school enrollment and completion. New Delhi: Oxford University Press; 2005.

12. Hungama Report. Hungama: Fighting Hunger \& Malnutrition. Naandi Foundation; 2011.

13. Chaturvedi S, Ramji S, Arora NK, Rewal S, Dasgupta R, Deshmukh V. Timeconstrained mother and expanding market: emerging model of undernutrition in India. BMC Public Health. 2016;16(1). https://doi.org/10.1186/ s12889-016-3189-4.

14. Gragnolati M, Bredenkamp C, Shekar M, Das Gupta M, Lee Y-K. India's undernourished children: a call for reform and action; 2006. https://doi.org/ 10.1596/978-0-8213-6587-8.

15. Kapil U. Integrated child development services (ICDS) scheme: a program for holistic development of children in India. Indian J Pediatr. 2002;69(7): 597-601. https://doi.org/10.1007/BF02722688.

16. Chakrabarti S, Raghunathan K, Alderman H, Menon P, Nguyen P. India's integrated child development services programme; equity and extent of coverage in 2006 and 2016. Bull World Health Organ. 2019;97(4):270-82. https://doi.org/10.2471/BLT.18.221135.

17. Frimpong JA, Helleringer S, Awoonor-Williams JK, Yeji F, Phillips JF. Does supervision improve health worker productivity? Evidence from the upper east region of Ghana: does supervision improve health worker productivity? Tropical Med Int Health. 2011;16(10):1225-33. https://doi.org/10.1111/j.13653156.2011.02824.x.

18. Manzi F, Schellenberg JA, Hutton G, Wyss K, Mbuya C, Shirima K, et al. Human resources for health care delivery in Tanzania: a multifaceted problem. Hum Resour Health. 2012;10(1). https://doi.org/10.1186/1478-449110-3.

19. Tani K, Stone A, Exavery A, Njozi M, Baynes CD, Phillips JF, et al. A time-use study of community health worker service activities in three rural districts of 
Tanzania (Rufiji, Ulanga and Kilombero). BMC Health Serv Res. 2016;16(1):1. https://doi.org/10.1186/s12913-016-1718-6

20. Sanou AK, Jegede AS, Nsungwa-Sabiiti J, et al. Motivation of community health workers in diagnosing, treating, and referring sick young children in a multicountry study. Clin Infect Dis. 2016;63(suppl 5): S270-5.

21. Saprii L, Richards E, Kokho P, Theobald S. Community health workers in rural India: Analysing the opportunities and challenges accredited social health activists (ASHAs) face in realising their multiple roles. Hum Resour Health. 2015;13(1). https://doi.org/10.1186/s12960-015-0094-3.

22. Bhutta ZA, Lassi ZS, Pariyo GW, Huicho L. Global experience of community health workers for delivery of health related millennium development goals: a systematic review, country case studies and recommendations for integration into National Health Systems. Geneva: WHO/Global Health Workforce Alliance; 2010

23. Haq Z, Iqbal Z, Rahman A. Job stress among community health workers: a multi-method study from Pakistan. Int J Ment Heal Syst. 2008:2:15.

24. Bhattacharyya $K$, Winch $P$, LeBan $K$, Tien M. Community health worker incentives and disincentives: how they affect motivation, retention, and sustainability. Arlington: Published by the Basic Support for Institutionalizing Child Survival Project (BASICS II) for the United States Agency for International Development; 2001.

25. Scott K, Shanker S. Tying their hands? Institutional obstacles to the success of the ASHA community health worker programme in rural North India. AIDS Care. 2010;22(Suppl 2):1606-12.

26. Bajpai N, Dholakia RH. Improving the performance of accredited social health activists in India. New York: Columbia Global Centers-South Asia, Columbia University; 2011.

27. NHSRC. ASHA which way forward: evaluation of ASHA program 2010-11. New Delhi; 2011. http://nhsrcindia.org/index.php?option= comcontent\&view=article\&id=286 [Accessed on 5 September 2019]

28. Afsar $\mathrm{H}$, Younus M. Recommendations to strengthen the role of lady health workers in the National Program for family planning and primary health Care in Pakistan: the health workers perspective. J Ayub Med College. 2005; 17(1):48-53.

29. Sennun P, Suwannapong N, Howteerakul N, Pacheun O. Participatory supervision model: building health promotion capacity among health officers and the community. Rural Remote Health. 2006;6:440.

30. World Health Organization. World health report - working together for health; 2006. http://www.who.int/whr/2006/whr06_en.pdf. Accessed on May 14, 2011.

31. World Health Organization. World health report - health systems financing: the path to universal coverage; 2010. http://www.who.int/whr/2010/whr10_ en.pdf. Accessed on May 14, 2011.

32. Lehmann U, Sanders D. Community health workers: what do we know about them? The state of the evidence on programmes, activities, costs and impact on health outcomes of using community health workers. Geneva: Evidence andlnformation for Policy, Department of Human Resources for Health, World Health Organization; 2007.

33. PATH CsVPa. Guidelines for implementing supportive supervision: a step-by-step guide with tools to support immunization; 2003. http:// www.path.org/vaccineresources/files/Guidelines_for_Supportive_ Supervision.pdf.

34. Whidden C, Kayentao K, Liu JX, Lee S, Keita Y, Diakité D, et al. Improving community health worker performance by using a personalised feedback dashboard for supervision: a randomised controlled trial. J Glob Health. 2018;8(2):1. https://doi.org/10.7189/jogh.08.020418.

35. Department of Forestry, Government of Madhya Pradesh [http://www.forest. mp.gov.in/Foresttable2.html].

36. De Costa A, Diwan V. Where is the public health sector? Public and private sector healthcare provision in Madhya Pradesh, India. Health Policy. 2007;84: 269-76.

37. Ministry of Health and Family Welfare, Government of India. India National Family Health Survey (NFHS4) 2015-16. Mumbai: International Institute for Population Sciences; 2017. http://rchiips.org/nfhs/NFHS-4Reports/India.pdf, accessed 27 February 2019

38. Nimmagadda S, Gopalakrishnan L, Avula R, et al. Effects of an mHealth intervention for community health workers on maternal and child nutrition and health service delivery in India: protocol for a quasi-experimental mixed-methods evaluation. BMJ Open. 2018;9:e25774. https://doi.org/10. 1136/bmjopen-2018-025774.
39. International Food Policy Research Institute (IFPRI), and Associates ResearchUganda (ARU). "Women's empowerment in agriculture (WEAI) pilot II for Uganda." Harvard Dataverse; 2015.

40. Kahneman D, Krueger AB, Schkade DA, Schwarz N, Stone AA. A survey method for characterizing daily life experience: the day reconstruction method. Science. 2004;306(5702):1776-80. https://doi.org/10.1126/science. 1103572.

41. Pentland WE, Harvey AS, Lawton MP, McColl MA, editors. Time use research in the social sciences. Dordrecht: Kluwer Academic Publishers; 1999.

42. National Institute of Public Cooperation and Child Development. Handbook for Anganwadi workers. India: New Delhi; 2006.

43. Malik A, Bhilwar M, Rustagi N, Taneja DK. An assessment of facilities and services at Anganwadi centers under the integrated child development service scheme in Northeast District of Delhi, India. Int J Qual Health Care. 2015;27(3):201-6. https://doi.org/10.1093/intghc/mzv028.

44. Thakare M, Kuril BM, Doible MK, et al. A study of functioning of Anganwadi centres of urban ICDS block of Aurangabad city. Indian J Prev Soc Med. 2011;42:253-8

45. Coutinho L, Bisht S, Raje G. Numerical narratives and documentary practices: vaccines, targets and reports of immunisation Programme. Econ Polit Wkly. 2000;35(8/9):656-66 Retrieved July 8, 2020, from www.jstor.org/stable/44 08962.

46. Haines A, Sanders D, Lehmann U, Rowe AK, Lawn JE, Jan S, et al. Achieving child survival goals: potential contribution of community health workers. Lancet. 2007;369(9579):2121-31. https://doi.org/10.1016/501406736(07)60325-0.

47. Mohanan P, Jain A, Kotian M, NK V. Are the anganwadi workers healthy and happy? A cross sectional study using the general health questionnaire (GHQ 12) at Mangalore, India. J Clin Diagn Res. 2012;6(7):1151-4.

48. Ramachandran D, Canny J, Das PD, Cutrell E. Mobile-izing health Workers in Rural India. In: Proceedings of the SIGCHI conference on human factors in computing systems; 2010. p. 1889-98.

49. Sharma R, Webster $P$, Bhattacharyya $S$. Factors affecting the performance of community health workers in India: a multi-stakeholder perspective. Glob Health Action. 2014;7:1.

50. Nayak N, Saxena NC. Implementation of ICDS in Bihar and Jharkhand. Econ Polit Wkly. 2006;41(34):3680-4 Retrieved from http://www.jstor.org/ stable/4418617.

51. Singh P, Masters WA. Impact of caregiver incentives on child health: evidence from an experiment with Anganwadi workers in India. J Health Econ. 2017;55:219-31. https://doi.org/10.1016/j.jhealeco.2017.07.005.

52. National Research Council. Time-use measurement and research: report of a workshop. Washington, DC: The National Academies Press; 2000. https://doi. org/10.17226/9866.

53. Melberg A, Diallo AH, Storeng KT, Tylleskär T, Moland KM. Policy, paperwork and 'postographs': global indicators and maternity care documentation in rural Burkina Faso. Soc Sci Med. 2018;215:28-35. https://doi.org/10.1016/j. socscimed.2018.09.001

\section{Publisher's Note}

Springer Nature remains neutral with regard to jurisdictional claims in published maps and institutional affiliations.

Ready to submit your research? Choose BMC and benefit from:

- fast, convenient online submission

- thorough peer review by experienced researchers in your field

- rapid publication on acceptance

- support for research data, including large and complex data types

- gold Open Access which fosters wider collaboration and increased citations

- maximum visibility for your research: over $100 \mathrm{M}$ website views per year

At BMC, research is always in progress.

Learn more biomedcentral.com/submission 